\title{
KAPITAL2: a study of treatment satisfaction reported by patients on lopinavir/r anchored regimens and physicians who provide HIV
}

\section{care}

\author{
JL Casado*1, L Griffa², E Cabrero², A Burgos² and M Norton ${ }^{3}$
}

Address: ${ }^{1}$ Hospital Ramón y Cajal, Madrid, Spain, ${ }^{2}$ Abbott Laboratories, S.A., Madrid, Spain and ${ }^{3}$ Abbott Labs., Chicago, USA

* Corresponding author

from Ninth International Congress on Drug Therapy in HIV Infection

Glasgow, UK. 9-13 November 2008

Published: 10 November 2008

Journal of the International AIDS Society 2008, I I (SuppI I):P80 doi: I0.I I86/I758-2652-I I-SI-P80

This abstract is available from: http://www.jiasociety.org/content/II/SI/P80

(C) 2008 Casado et al; licensee BioMed Central Ltd.

\section{Purpose of the study}

$\mathrm{LPV} / \mathrm{r}$-based HAART is a common treatment regimen for HIV-1 disease. We conducted a large observational study of patients currently taking LPV/r-based therapy (LPV/r T) in an attempt to describe patient satisfaction or lack thereof with LPV/r T. We concurrently conducted a physician survey to describe physician impressions of their patients' satisfaction.

\section{Methods}

Patients self-administered three questionnaires (qst.) at one visit: modified HIVTSQ treatment satisfaction qst.1; EuroQoL quality of life (QoL) qst.2; and the 5-item qst. further probing QoL, adherence, daily activity, tolerability and satisfaction with treatment. Physicians independently completed the 5-item qst. It was a multicenter cross-sectional observational study throughout Spain (participants size/center limited to reduce regional/center bias). Patients were required to be taking a LPV/r (tablets) based therapy for $>1$ month. Dataset analysed as a whole, and both by naïve- vs. ARV-experienced, and by duration of LPV/r T (Cohort CH1: 1-3 months; CH2: >3 months <2 years and $\mathrm{CH} 3:>2$ years).

\section{Summary of results}

1,109 patients and 97 doctors participated. Patient mean age 42.6 years; $27.4 \%$ female, and $31.5 \%$ were naïve prior to LPV/r T. Patients by duration of exposure ; $\mathrm{CH} 1: 315$, CH2: 394, CH3: 400. Mean HIVTSQ scores (over 100) per dimension were: general/clinical satisfaction, $83.0 \pm 15.4$; lifestyle, $75.2 \pm 16.5$; and overall satisfaction, $79.5 \pm 14.0$. Mean EuroQoL score (over 10) was $7.40 \pm 1.64$. For the 5 item qst. patient reporting was, $90.9 \%$ no-very little impact on QoL, 80.7\% considered LPV/r T well-very well tolerated, $89.4 \%$ were well-very well compliant, $88.8 \%$ had no-very few difficulties on daily activities, and $82.7 \%$ high-very high satisfaction on LPV/r T. Corresponding physicians' answers were 86.7\%, 85.4\%, 87.0\%, 88.9\% and $79.0 \%$, respectively (high concordance with patient's findings in reporting of satisfaction was shown). Findings from the HIVTSQ did not show significant satisfaction differences between previously ARV-naïve vs. -experienced patients. Total satisfaction scores were greater with time on LPV/r T $(\mathrm{CH} 3>2>1$, p $<0.001)$.

\section{Conclusion}

Overall, reported patient satisfaction level with $\mathrm{LPV} / \mathrm{r} \mathrm{T}$ was high. Not surprisingly, patients with the longest exposure duration reported the highest levels of satisfaction. Additional patient satisfaction studies conducted among patients on differing anchor antiretrovirals would provide further context, comparison, and interpretation for these $\mathrm{LPV} / \mathrm{r}$ treatment satisfaction findings.

\section{References}

I. Woodcock A, Bradley C: Validation of the HIV treatment satisfaction questionnaire (HIVTSQ). Qual Life Res 200I, I 0:5 I7-3I.

2. The EuroQoL Group: EuroQoL - A new facility for the measurement of health-related quality of life. Health Policy 1990, 16: 199-208. 